\title{
Origens da vida no contexto cósmico: o primeiro MOOC em astronomia desenvolvido no Brasil
}

\author{
Origins of life in the cosmic context: the first MOOC in astronomy developed in Brazil
}

\author{
Rodrigo de Souza*1@, Elysandra Figueredo Cypriano ${ }^{1}$ \\ ${ }^{1}$ Universidade de São Paulo, Instituto de Astronomia, Geofísica e Ciências Atmosféricas (IAG), São Paulo, SP, Brasil
}

Recebido em 27 de setembro de 2019. Revisado em 07 de novembro de 2019. Aceito em 22 de novembro de 2019

O MOOC "Origens da vida no contexto cósmico" foi a primeira iniciativa de Astronomia em língua portuguesa neste formato. Seu lançamento ocorreu em junho de 2016, contando inicialmente, com mais de 4.000 alunos, número que foi aumentando gradativamente (e cumulativamente) até a última sessão analisada (agosto, 2019). Nesse artigo será apresentada a metodologia utilizada para a criação do MOOC que, atualmente, já atendeu a mais de 150 mil alunos, além de uma reflexão sobre seu desenvolvimento de forma acompanhada ou independente do apoio de um tutor. Como resultados, identificou-se que a taxa de conclusão do curso esteve em torno de $9 \%$, o que corrobora os dados da literatura, além da predominância de alunos com formação superior e do gênero masculino. O nível de satisfação dos alunos com o curso foi elevado: em uma escala de 0 a 5 , a satisfação foi avaliada em 4,8 . Além disso, o curso já transcende a barreira do mundo virtual e tem sido empregado como ferramenta de auxílio à aprendizagem em escolas de ensino fundamental e médio.

Palavras-chave: MOOC; design instrucional; astronomia; astrobiologia.

\begin{abstract}
"Origins of life in the cosmic context" was the first one Astronomy MOOC in Portuguese-language. The launch took place in June 2016, initially counting more than 4,000 students, which gradually (and cumulatively) until the last session analyzed (august, 2019). This paper shows the MOOC methodology that already attended more than 150 thousands students and a discussion about the maintenance in a mentored and independent way. As a result, we found that the course completion rate was around $9 \%$, which corroborates the literature, in addition to the predominance of higher education students and males. The students satisfaction level was high: on a scale of 0 to 5 , satisfaction was assessed at 4.8. Moreover, the course has already transcended the virtual world barrier and have been used as a tool to aid astronomy learning in elementary and middle schools.
\end{abstract}

Keywords: MOOC; instructional design; astronomy; astrobiology.

\section{Introdução}

MOOC - massive open online course (ou curso aberto, massivo e online, em português) é um formato de curso baseado em plataformas online que atende uma quantidade expressiva de alunos simultaneamente [1] Os MOOC originaram-se do trabalho de Siemens e Downes com a teoria do aprendizado conectivista [2]. Na perspectiva do conectivismo, vivemos em uma sociedade altamente conectada através das redes formadas na internet e o estudante neste mundo contemporâneo interage e participa ativamente na construção e no aumento da complexidade destas redes do saber [3]. O aprendizado então, passa a ser realizado a partir das necessidades específicas deste estudante neste ambiente em rede, portanto, um novo contexto social demanda uma nova estratégia de ensinar e aprender [4]. Para Siemens e Downes esta nova estratégia é o MOOC [5].

Os MOOC normalmente são classificados da seguinte forma: a) cMOOC: formato originado diretamente da abordagem conectivista. Os cMOOC caracterizam-se pela formação de redes de aprendizado, nas quais a apresentação de conteúdos por vídeo é o aspecto menos relevante. Neste formato o aprendizado ocorre por meio dos objetivos de aprendizagem, formados pelo próprio aluno e em sua capacidade de construir ligações com outros indivíduos na rede. Desta forma, o aluno aprende por meio das interações com outros alunos. Este formato é pouco explorado atualmente [6].

b) xMOOC: este formato é empregado nas plataformas (como o Coursera, por exemplo) e baseia-se na apresentação de conteúdos por vídeo, realização de quizzes e interações restritas aos fóruns. Neste formato o aprendizado ocorre, na maioria dos casos, individualmente, uma vez que não há a necessidade de interagir, nem mesmo nos fóruns, para aprender, e que os conteúdos estão disponíveis em sequências logicamente encadeadas, as quais tendem a suprimir a grande necessidade de interação para que o aprendizado ocorra [7].

*Endereço de correspondência: rodrigosouza.etec@gmail.com 
A Tabela 1 exemplifica as principais características dos dois formatos.

O xMOOC é considerado uma "derivação" do cMOOC, em uma abordagem mais padronizada e abrangente, já que o cMOOC seria mais dinâmico, personalizado e demandaria maior tempo de interação por parte do aluno [8]. No caso dos xMOOC, especificamente, o público característico é composto por alunos com formação em nível superior e com alguma ocupação profissional [9]. Estes alunos utilizam os MOOC como mecanismo para a atualização profissional ou instrumento de aprendizado para conteúdos de seu interesse. Um dos pontos que atraem estes alunos aos xMOOC é a completa flexibilidade do curso em termos de apresentação de conteúdos e realização de atividades [1], permitindo desta forma que, alunos com outras ocupações possam, em seus momentos livres, realizar o curso sem impedir a realização de outras atividades. O MOOC "Origens da Vida no Contexto Cósmico" foi desenvolvido no formato de um xMOOC de forma que nos referimos a essa modalidade como MOOC no conteúdo que segue neste artigo.

\section{O MOOC "origens da vida no contexto cósmico"}

O curso "Origens da vida no contexto cósmico" originouse como produto final de um trabalho do Mestrado Profissional em Ensino de Astronomia do IAG/USP. Com duração de quatro semanas (duas horas de dedicação sugerida por semana), o curso foi organizado de forma a contar com uma dedicação de oito horas dos cursistas. O artigo "Origens da vida"[10] foi utilizado para estruturar o curso, no entanto, o tema vida foi tratado de forma interdisciplinar envolvendo a participação de especialistas das várias áreas correlatas e também entrevistas que tinham como objetivo apresentar a fronteira do conhecimento dos tópicos semanais. Para a coleta de dados e avaliação que deram suporte à dissertação de mestrado, o curso foi oferecido em uma edição acompanhada por tutoria na plataforma Coursera em junho de 2016. Desde então o curso tem sido sistematicamente oferecido na mesma plataforma a cada 2 meses de forma contínua

Tabela 1: cMOOC e xMOOC

\begin{tabular}{|c|c|}
\hline cMOOC & $\mathrm{xMOOC}$ \\
\hline $\begin{array}{l}\text { Aprendizagem a partir do com- } \\
\text { partilhamento }\end{array}$ & $\begin{array}{l}\text { Aprendizagem a partir da ex- } \\
\text { posição do conteúdo pelo pro- } \\
\text { fessor }\end{array}$ \\
\hline $\begin{array}{l}\text { Aprendizagem ativa e partici- } \\
\text { pativa }\end{array}$ & Aprendizagem linear e guiada \\
\hline $\begin{array}{l}\text { As tarefas partem dos questio- } \\
\text { namentos dos participantes }\end{array}$ & $\begin{array}{l}\text { As tarefas são padronizadas e } \\
\text { visam a verificação do conhe- } \\
\text { cimento adquirido }\end{array}$ \\
\hline $\begin{array}{l}\text { Comunicação é a principal } \\
\text { forma de conexão com os de- } \\
\text { mais participantes da comuni- } \\
\text { dade de aprendizado }\end{array}$ & $\begin{array}{l}\text { Comunicação não é essencial } \\
\text { para o aprendizado. Este pode } \\
\text { até ocorrer de forma indivi- } \\
\text { dual }\end{array}$ \\
\hline
\end{tabular}

Fonte: adaptado da referência [4]. (também conhecida como on demand) e sem acompanhamento de um tutor. Nessa seção será apresentado de forma detalhada todos os passos necessários para o desenvolvimento do curso, que demandou cerca de um ano, entre o planejamento e o lançamento. Os procedimentos aqui apresentados podem dar subsídios para a construção de MOOCs independente dos conteúdos e plataforma utilizada para o oferecimento.

Como qualquer outro curso EaD, um MOOC requer um modelo de funcionamento e apresentação, denominado design instrucional [11]. Existem diversas propostas de modelos de design instrucional, com focos distintos, no entanto, todas elas tem o objetivo de proporcionar uma sequência coerente de desenvolvimento do MOOC, empregando o mínimo de recursos no menor espaço de tempo possível [12]. No início do planejamento de "Origens da vida no contexto cósmico", nos deparamos com diversos modelos de design instrucional, no entanto, devido às características únicas do projeto e seu pioneirismo, além de nossas restrições de recursos, foi necessário o desenvolvimento de adequações desses modelos aos propósitos do projeto. Optamos portanto por um modelo híbrido entre a perspectiva de Kellog [13] e da Universidade de British Columbia [14], tal como apresentado na Tabela 2.

Na Tabela 2 apresentamos nas linhas, as etapas temporais sequenciais do desenvolvimento do MOOC e, nas colunas, os objetivos pedagógicos a serem alcançados em cada uma destas etapas. O modelo de design instrucional apresenta "o que" e "quando", no entanto, o principal elemento é o "como" será feito. Para isso, delineamos, para cada objetivo pedagógico, uma resposta prática que foi implementada nas respectivas fases, conforme descrito na Tabela 3 .

Uma vez definidos os objetivos pedagógicos, o próximo passo foi delinear as metas de aprendizagem, ou seja, o que se espera que os alunos de "Origens da vida no contexto cósmico" aprendam a partir de cada módulo do curso, sempre levando em consideração que, por se tratar de um curso de conteúdo amplo, o enfoque na interdisciplinaridade e na capacidade de compreender os fenômenos de forma sistêmica, identificando as relações de causa e efeito entre os diversos conhecimentos apresentados, devem ser prioridades. A Tabela 4 apresenta as metas de aprendizagem propostas.

Após a conclusão do planejamento, inicia-se a etapa de realização, que consiste na elaboração de roteiros, gravação e edição de vídeos, elaboração de quizzes e revisão de conteúdo, para finalmente, implementar os recursos desenvolvidos na plataforma e, no nosso caso, o lançamento formal na plataforma Coursera.

\subsection{As Ciências apresentadas de forma interdisciplinar}

Os conteúdos explorados no MOOC Origens da Vida contemplaram de forma interdisciplinar assuntos de Astronomia, Física, Biologia, Química entre outras áreas 
Tabela 2: Modelo de design instrucional desenvolvido para o curso "Origens da vida no contexto cósmico"

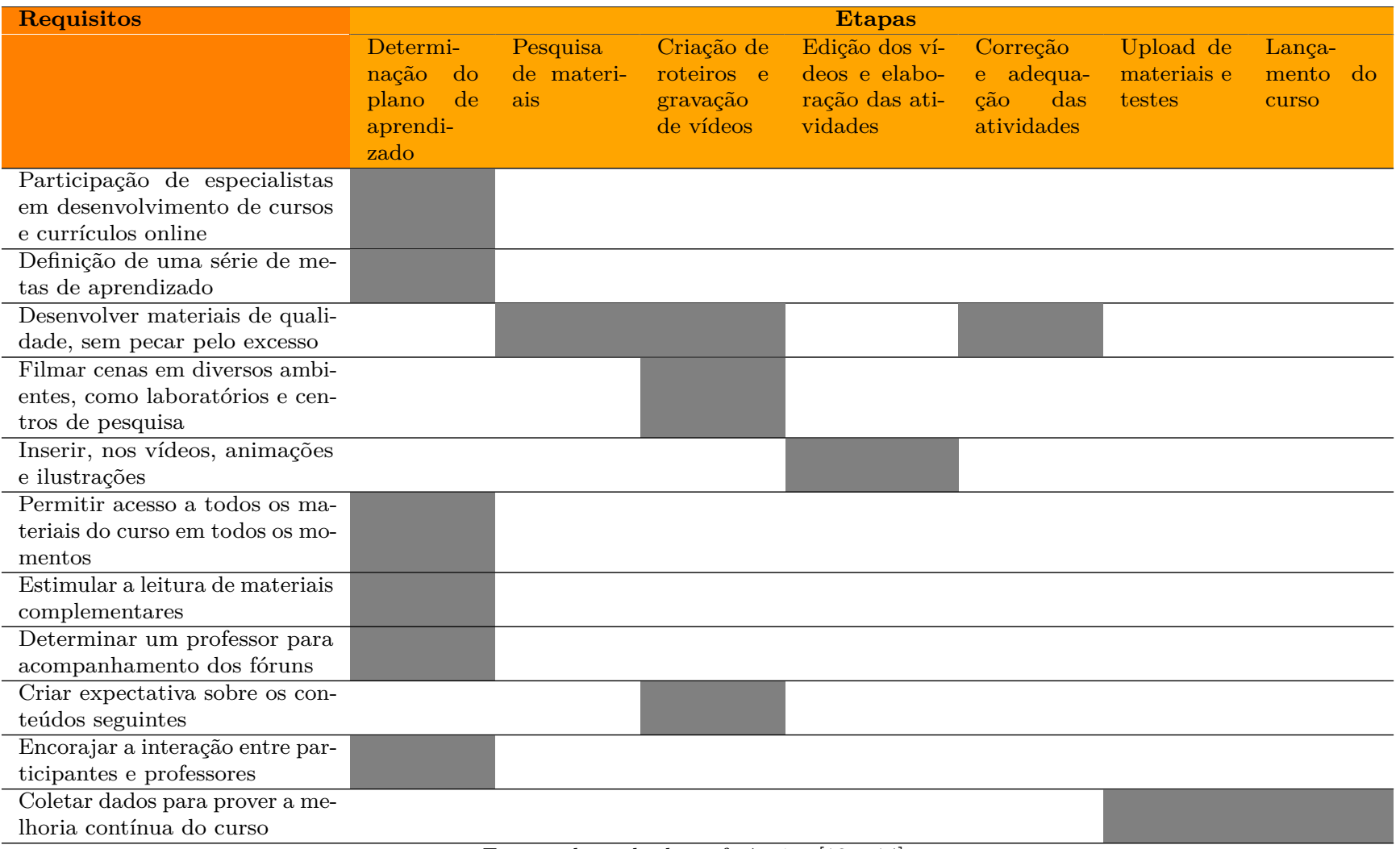

Tabela 3: Atendimento aos objetivos pedagógicos do MOOC "Origens da vida no contexto cósmico"

\section{Requisitos}

Participação de especialistas em desenvolvimento de cursos e currículos online

Definição de uma série de metas de aprendizado

Desenvolver materiais de qualidade, sem pecar pelo excesso

Filmar cenas em diversos ambientes, como laboratórios e centros de pesquisa

Inserir, nos vídeos, animações e ilustrações

Permitir acesso a todos os materiais do curso em todos os momentos

Estimular a leitura de materiais complementares

Determinar um professor para acompanhamento dos fóruns

Criar expectativa sobre os conteúdos seguintes

Encorajar a interação entre participantes e professores

Coletar dados para prover a melhoria contínua do curso

\section{Como atender estes requisitos?}

Envolver professores de Biologia, Astronomia e Astrobiologia explicando a eles a ideia do MOOC e como sua participação ocorrerá. O artigo "Origens da vida"(Damineli e Damineli, 2007) foi o texto estruturante do curso.

Separar o curso por semanas (4 no total), identificando os pontos chave (do conteúdo) de cada semana.

Envolver os professores no desenvolvimento dos roteiros e materiais de apoio para garantir a intersecção e continuidade das aulas. Para recursos audiovisuais, de uso livre, sem direitos autorais.

Devido às restrições técnicas, as locações de filmagem foram em estúdio, recepção do IAG e Laboratório LASA (cortesia do professor Sergio Pilling e da Univap). Entrevistas com especialistas reforçaram os conteúdos da semana como estratégia de trazer questões da fronteira do conhecimento nos assuntos semanais

Buscar ilustrações auxiliares nas ferramentas de busca de conteúdo livre. Optamos por utilizar apenas materiais com liberdade de uso (licença creative commons).

Disponibilizar materiais auxiliares para download na primeira aula. Vídeos podem ser baixados livremente nas plataformas de MOOC

Deixar claro que o artigo "Origens da vida"(Damineli e Damineli, 2007) é uma leitura relevante e importante para estruturar os conhecimentos que foram aprofundados no curso.

Em um primeiro oferecimento, para coleta de dados e avaliação da aplicabilidade do MOOC, foi designado um tutor para o acompanhamento dos fóruns e gestão do curso na plataforma.

Aulas de encerramento da semana foram estruturadas como um "teaser"para estimular os alunos a continuarem no curso na próxima semana. Além disso, essas aulas tinham como objetivo revisar e integrar os conteúdos abordados durante a semana.

Em seu primeiro oferecimento, o tutor responsável pelo fórum atuou no sentido de estimular a participação dos alunos em discussões, com e-mails e intervenções diretas. A coleta foi feita através dos dados fornecidos pela própria plataforma assim como anotação de falas e resultados dos questionários. A análise dos dados favoreceu correções e implementações adicionais, no contexto deste trabalho de pesquisa 
Tabela 4: Metas de aprendizagem do MOOC "Origens da vida no contexto cósmico"

\begin{tabular}{|c|c|c|}
\hline Objetivos & & Metas de aprendizado \\
\hline Semana 1 & $\begin{array}{l}\text { Apresentar o universo, nossa localização } \\
\text { e a vida na Terra }\end{array}$ & $\begin{array}{l}\text { O aluno deve ser capaz de compreender as escalas de medida cósmicas, } \\
\text { a idade do universo e compreender a variedade de vida na Terra }\end{array}$ \\
\hline Semana 2 & $\begin{array}{l}\text { Apresentar a origem dos elementos quí- } \\
\text { micos e do sistema solar }\end{array}$ & $\begin{array}{l}\text { O aluno deve ser capaz de compreender as escalas de tempo da } \\
\text { formação dos elementos CHON, o processo de fusão nuclear e a } \\
\text { formação do sistema solar a partir de uma nebulosa primordial }\end{array}$ \\
\hline Semana 3 & $\begin{array}{l}\text { Apresentar a ausência de fósseis da pri- } \\
\text { meira forma de vida na Terra. O surgi- } \\
\text { mento de RNA e DNA e o conceito de } \\
\text { Zona de Habitabilidade }\end{array}$ & $\begin{array}{l}\text { O aluno deve ser capaz de compreender o conceito de fóssil, seu } \\
\text { processo de identificação, além das hipóteses sobre a formação dos } \\
\text { ácidos nucléicos e sua característica de mantenedor das características } \\
\text { dos seres vivos e transcritores destas características, além de como a } \\
\text { vida pode surgir em outros pontos do universo com características } \\
\text { propícias }\end{array}$ \\
\hline Semana 4 & $\begin{array}{l}\text { Apresentar a possibilidade de a vida sur- } \\
\text { gir em outros pontos do universo, os mé- } \\
\text { todos de detecção de exoplanetas e de } \\
\text { bioassinaturas e as tecnologias promisso- } \\
\text { ras nesta busca }\end{array}$ & $\begin{array}{l}\text { O aluno deve compreender o conceito de exoplaneta, seus métodos } \\
\text { de detecção, bem como o conceito de bioassinatura e os esforços } \\
\text { no desenvolvimento de tecnologias de busca e identificação destas } \\
\text { bioassinaturas }\end{array}$ \\
\hline
\end{tabular}

Fonte: os autores.

do saber. Esses conteúdos, presentes nos currículos escolares, foram distribuídos ao longo das semanas com o objetivo de apresentar os mais recentes avanços científicos na compreensão do tema central que nos levará a compreender de maneira mais ampla e crítica os aspectos envolvidos no surgimento de vida na Terra e no possível surgimento de vida em outros planetas.

Ao longo do curso exploramos o fluxo do "micro ao macro", ou seja, tratando das partículas subatômicas aos aglomerados galácticos e à própria dinâmica do universo como um todo. Iniciamos nossa jornada, na primeiro módulo do curso, apresentando a diversidade biológica da vida em nosso planeta e questionando a sua origem como sendo um ato da criação ou o resultados de transformações químicas. Exploramos as escalas de distância e apresentamos "novas réguas" para a medir as distâncias cósmicas e como relacionamos essas distâncias com a medida do tempo. Apresentamos a formação de sistemas planetários como um processo natural orquestrado pela lei da gravitação universal da Física, e que o processo físico que deu origem ao Sistema Solar é o mesmo que ocorre na formação da grande maioria das estrelas que vemos no céu noturno. No primeiro módulo procuramos redimensionar a ideia de universo, apresentamos nossa posição em escala cosmológica, e ao mesmo tempo mostramos que este é repleto dos ingredientes essenciais para a origem da vida.

O segundo módulo do curso explorou a química que compõe o universo que conhecemos e apresentou a origem dos elementos químicos como um processo físico que ocorre no núcleo das estrelas e, no caso de elementos mais pesados que o Ferro, em eventos mais energéticos como explosões de supernovas e encontro de estrelas de nêutrons. Apresentamos o tema de fusão termonuclear como o processo físico essencial para a nucleossíntese no universo, e como isso se associa com o ciclo da vida das estrelas, mantendo os objetos estelares que se sustentam pelo equilíbrio hidrostático. Formada a estrela, a partir desse equilíbrio entre o colapso gravitacional e a pressão da radiação dos fótons produzidos no seu núcleo, apresentamos a formação de todos os demais componentes do nosso sistema planetário como um processo colisional, no caso dos planetas rochosos, cometas e asteroides, ou como um processo conhecido como instabilidade de disco, no caso dos planetas gasosos. Toda a dinâmica do movimento desses corpos ao redor do Sol é regida pelas leis da mecânica clássica da Física. Encerramos nosso conteúdo do segundo módulo apresentando a primeira forma experimental usada para simular e explicar a origem da vida na Terra - o experimento de Urey e Miller - e porque este experimento falhou nesta explicação.

O terceiro módulo foi dedicado à busca de evidências e pistas que nos levam a reconstruir a história da vida na Terra, em uma abordagem mais voltada às ciências biológicas, ou paleontologia. Exploramos como e onde encontrar evidências e como podemos explorá-las para entender como a vida se originou na Terra e como evoluiu até os dias de hoje.

No último módulo do curso exploramos a vida como sendo algo mais abundante do que a percebemos. Exploramos o conceito de exoplanetas e apresentamos a tecnologia de fronteira que está voltada a obtenção de novas pistas para a nossa compreensão da vida em um contexto mais amplo. Exoplanetas, grandes telescópios e a compreensão da vida como um fenômeno cósmico finalizaram nosso curso, onde buscou-se traçar relações de causalidade entre os diversos saberes, permitindo ao aluno uma percepção global do assunto.

\section{Análise dos dados após o lançamento do MOOC "origens da vida no contexto cósmico"}

O curso foi lançado em 20 de junho de 2016 e sua primeira sessão acompanhada por um tutor terminou em 25 de julho do mesmo ano [1]. Após essa primeira sessão de avaliação, o curso entrou em processo de oferecimento on demand, ou seja, nesta sistemática a plataforma abre 
sessões contínuas do curso automaticamente, conforme o número de interessados em sua realização. Desde seu lançamento, o curso tem estado ativo na plataforma Coursera, tendo figurado como um dos mais procurados nesta plataforma em língua portuguesa. Apresentamos a seguir resultados de uma análise quantitativa com dados fornecidos e extraídos diretamente da plataforma Coursera referentes às primeiras 33 sessões de oferecimento do curso. O Gráfico 1 demonstra a evolução do número total de alunos a partir dos ingressantes no curso por sessão, partindo da primeira, com término em julho de 2016 até a última (avaliada), com término em março de 2019.

O gráfico 1 mostra o aumento cumulativo do número de alunos por sessão. O valor total passou de 4.121 na primeira sessão para mais de 150.000 na última sessão avaliada, representando um incremento de mais de 38 vezes. Os dados indicam que, mesmo o curso não sendo mais uma novidade (quase três anos após seu lançamento), ainda sim, há um interesse e demanda muito grande por parte do público que se renova. A análise da tendência mostra que ainda não houve saturação da demanda, não havendo indícios de que haverá estagnação nos próximos oferecimentos.

O Gráfico 2 caracteriza nossos cursistas em gênero, formação e ocupação. No aspecto gênero, observa-se a predominância do gênero masculino, corroborando o resultado apontado por Christensen [9] com cerca de 58\% dos alunos sendo do gênero masculino porém, em nosso caso esse percentual é consideravelmente maior (70\%). No que se refere a formação dos cursistas, verificamos que a maioria dos alunos $(68 \%)$ possui nível superior, corroborando os dados encontrados na literatura [15] com cerca de $70 \%$ de alunos tendo formação de nível superior. Sobre a ocupação atual de nossos cursistas, a maioria dos alunos (89\%) declarou alguma ocupação, sendo que des- tes, a maioria é atuante no mercado de trabalho (68\% do total de alunos), isso reforça a ideia de que os MOOC são um formato que atende as necessidades de aprendizado de indivíduos com alguma ocupação, os quais buscam este tipo de curso devido à flexibilidade de horários [16].

Por se tratar de um curso com número ilimitado de estudantes, uma avaliação relevante a ser feita na aplicação de um MOOC é a taxa de concluintes do curso. Considera-se como concluinte o indivíduo que visualizou todos os vídeos completamente e realizou todas as atividades com nota adequada para aprovação [17]. Neste ponto, verifica-se que a taxa de concluintes está na média de $12 \%$ nas sessões analisadas. Este número corrobora os índices encontrados na literatura e, embora uma análise quantitativa expresse um baixo nível de conclusão, é importante ressaltar que em estudo sobre o perfil de alunos em diversos MOOC, Anderson et al. [17], identificaram que cerca de $89 \%$ dos alunos de um MOOC possuem perfis de baixa interação com o curso, normalmente voltados apenas a visualização dos vídeos. Isso indica que, embora poucos concluam os cursos, a maioria apenas interessa-se pelos conteúdos, mas não interagem nos fóruns e não desenvolvem as avaliações para aprovação. Ao mesmo tempo que não podemos afirmar que esses estudantes de fato tiveram um aproveitamento adequado do material visualizado, não se pode afirmar também que estes $89 \%$ (no caso de "Origens da vida no contexto cósmico", 91\%) não aprenderam nada a respeito do conteúdo proposto após visualizar todo o material. Estes alunos podem ter necessidades pontuais de aprendizado que, teoricamente, poderiam ser sanadas apenas com a visualização dos vídeos e ao mesmo tempo não ter interesse em aquisição de certificados, tornando as avaliações desnecessárias.

A Tabela 5 apresenta a relação dos acertos dos alunos, que concluíram o curso integralmente, nos quizzes. Aplicando o índice de correlação Pearson, chegou-se a um

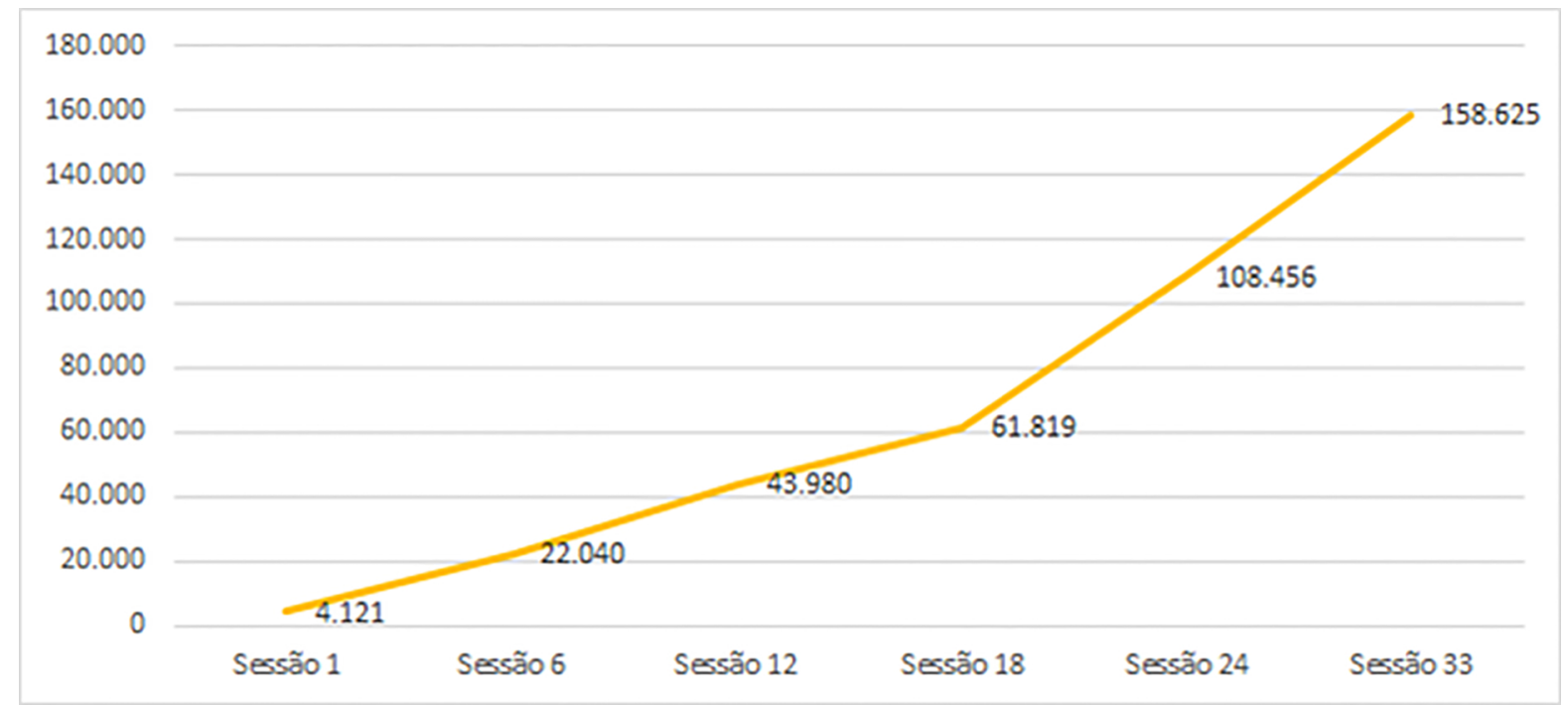

Gráfico 1: Número de alunos que cursaram o MOOC "Origens da vida no contexto cósmico" ao longo do tempo de oferecimento Fonte: os autores. 


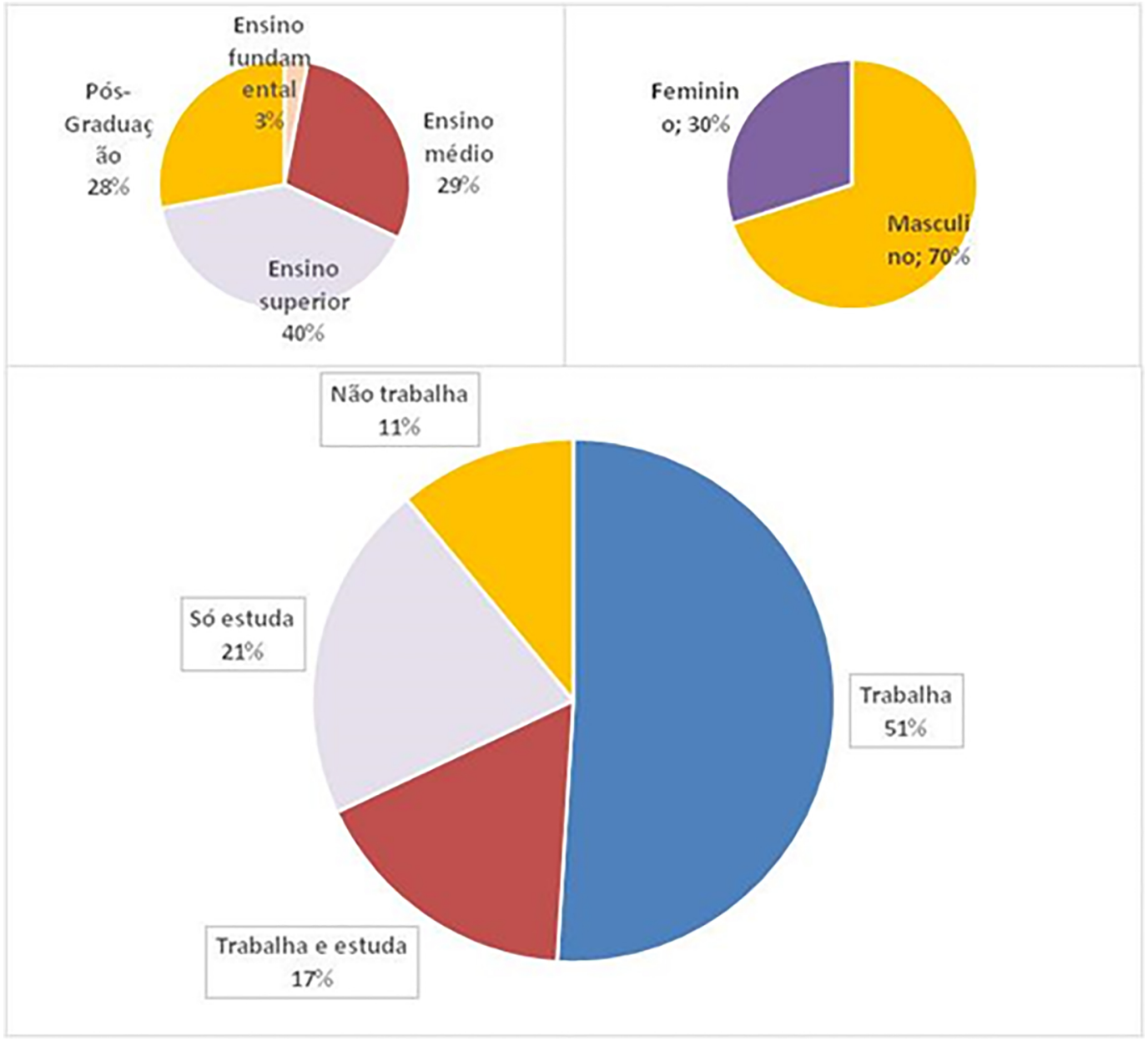

Gráfico 2: Caracterização dos alunos cursistas por gênero, formação e ocupação. Fonte: os autores.

Tabela 5: Nível de acertos $\times$ Quantidade de questões

\begin{tabular}{lll} 
Semana & Número de questões & $\%$ Médio de Acertos \\
\hline 1 & 10 & $75 \%$ \\
2 & 6 & $84 \%$ \\
3 & 10 & $77 \%$ \\
4 & 6 & $85 \%$ \\
\hline \multicolumn{2}{c}{ Fonte: os autores. }
\end{tabular}

coeficiente de -0,97, o que indica uma correlação inversamente proporcional, ou seja, a tendência é que, quanto maior o número de questões, menor a probabilidade de acertos. Com base nisso, aplicou-se o cálculo da regressão linear, com o objetivo de determinar a equação que descreve a projeção dos acertos em função da quantidade de questões e, posteriormente, a determinação do número ótimo de questões de um quizz, de forma a maximizar o número de acertos. Como resultado, chegou-se ao número de 3 questões por quizz, que segundo a estimativa, levariam a um nível de acertos de $98 \%$, corroborando o proposto por Skrypnik [18].

Outra análise interessante que pode ser extraída dos dados da plataforma é o alcance geográfico do curso, que pode ser observado no Gráfico 3. O que se verifica é a predominância de alunos brasileiros.
Cabe ressaltar nesse ponto que, mesmo não havendo muitas opções de MOOC sendo oferecido em língua portuguesa, o Brasil está entre os países com maior número de usuários de MOOCs nas grandes plataformas [19]. Por outro lado, a reduzida participação de estudantes de outros países se explica no fato de que o curso surgiu apenas em português e que sua divulgação ocorreu de forma relativamente contida, apenas em círculos relativamente restritos. Dessa forma, a participação de alunos de outros países foi modesta porém algo surpreendente tendo em vista a falta de divulgação e que, somente a partir da $4^{\circ}$ sessão de seu lançamento, as primeiras legendas em outros idiomas, realizadas por voluntários do Coursera, começaram a ser implementadas.

Quanto à avaliação do curso por parte dos alunos, o Coursera dispõe de uma escala com pontuação de 0 a 5 e o curso "Origens da vida no contexto cósmico" obteve mantém até o presente a nota 4,8. Além disso, existe espaço para depoimentos de alunos, os quais tem sido em sua grande maioria, positivos em relação a essa iniciativa em língua portuguesa. 


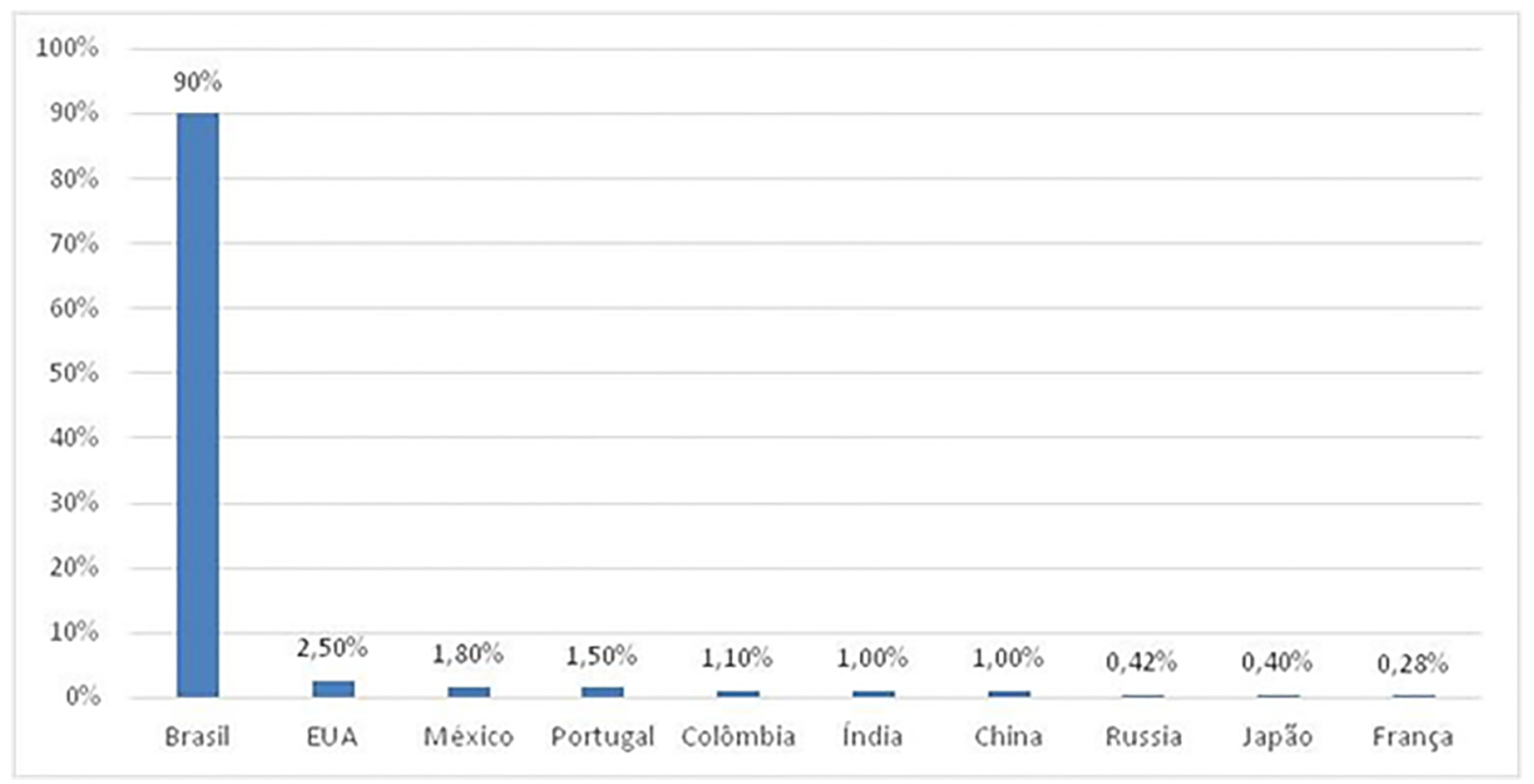

Gráfico 3: Percentual de alunos que cursaram o MOOC "Origens da Vida" por país de origem. Fonte: os autores.

\section{Conclusão}

O desenvolvimento do MOOC "Origens da vida no contexto cósmico" foi um trabalho complexo e desafiador, tendo em vista a ausência de precedentes nacionais em astronomia que pudessem servir de referência, além disso, a falta de um modelo de design instrucional adequado ao curso, tornou o processo ainda mais intrincado, uma vez que coube a nós, não só o desenvolvimento da parte conceitual do curso, mas o desenvolvimento de um modelo de projeção do curso, que posteriormente se mostrou adequado como estrutura de design instrucional. Ressalta-se que, "Origens da vida no contexto cósmico", contribuiu não somente à área de ensino de Astronomia, como também à própria pedagogia dos MOOC, uma vez que disponibilizamos uma ferramenta que pode ser empregada em outros projetos, não somente relacionados à Astronomia.

De uma forma geral, os dados encontrados estão de acordo com estudos similares realizados ao redor do mundo. Neste ponto, cabe frisar o trabalho de Impey et al. [20], que tratou de um MOOC em Astronomia desenvolvido nos Estados Unidos, em um período próximo ao do lançamento de "Origens da vida". No estudo citado, os dados de conclusão (cerca de 17\%) e de alunos com formação superior e pós-graduação (cerca de 74\%), se mostram muito próximos dos dados encontrados neste trabalho, o que inclusive, já foi identificado em outras pesquisas já citadas. O fato é que, ao se projetar um MOOC, espera-se um público misto, que seja representativo da população, o que Mahoney [21] denomina de público outreach, ou seja, público geral, não especializado. O que se observa é que os MOOC, de certa forma, tem maior apelo entre os público midreach (iniciados no assunto) e inreach (especialistas), o que não é um aspecto negativo, mas pode nortear de forma mais adequada as estratégias de desenvolvimento e a profundidade na abordagem dos conteúdos. No caso do MOOC que desenvolvemos apostamos em uma abordagem mais ampla e menos específica do conteúdo, trazendo sempre uma perspectiva do que é atual e de fronteira, o que se mostrou adequado aos nossos cursistas, dada a avaliação bastante positiva do curso.

Outro ponto que merece ser verificado é o processo de interação entre os alunos e o MOOC, de forma a compreender melhor o percentual de $90 \%$ de alunos que não seguem todas as atividades propostas que, conforme já citado, não podem ser considerados como evadidos, mas cuja proporção tem considerável peso sobre o total de alunos concluintes.

Ao se compreender estes dois aspectos (característica de formação do público e nível de interação), seria possível formular métodos mais eficazes para o projeto pedagógico e design instrucional do MOOC, de forma que este pudesse ser realmente, uma iniciativa voltada ao público geral e com um número razoável de alunos que seguem o programa do curso.

A partir da análise dos depoimentos, observou-se uma participação expressiva de professores de ensino fundamental e médio, que, em muitos casos, demonstraram intenção de utilizar o curso como um recurso didático para suas aulas, transcendendo, dessa forma, as fronteiras naturais de um MOOC. Com relação a este último aspecto, iniciamos um trabalho exploratório sobre a aplicação do MOOC "Origens da vida no contexto cósmico" como um recurso didático para alunos do ensino médio, dentro do que podemos classificar como ensino híbrido. Entre outros resultados, observou-se que a aplicação deste MOOC como recurso auxiliar de ensino mostrou-se positiva, auxiliando os alunos envolvidos na compreensão 
dos fenômenos relacionados à origem da vida na Terra. Um estudo mais detalhado sobre essa aplicação deverá nortear nossas próximas pesquisas.

Ressalta-se que, ao se comparar os resultados da primeira sessão (2016), que teve acompanhamento dos pesquisadores, com as demais sessões, que fluíram de forma autônoma, não se identificou qualquer diferença expressiva no comportamento de nenhum dos indicadores. Isso pode indicar que nesta modalidade, quando bem desenvolvida, a participação dos tutores pode não ser um aspecto determinante para o andamento do curso.

Por fim, considera-se que a grande aceitação do curso por parte dos alunos e as boas repercussões na comunidade acadêmica são fatores que indicam que, mesmo com todas as dificuldades encontradas e com os problemas ainda a serem corrigidos, "Origens da vida no contexto cósmico" tem cumprido seu papel de instrumento massivo de difusão da Astronomia, estabelecendo uma relação direta da universidade com a sociedade, sem intermediários. Essa abordagem, como foi dito, tem ido além do ambiente virtual e se instalado também nas salas de aula como recurso auxiliar de aprendizagem.

\section{Referências}

[1] R. Souza, Origens da vida no contexto cósmico: estudo sobre o desenvolvimento de MOOC em Astronomia. Dissertação de Mestrado, Universidade de São Paulo, São Paulo (2016).

[2] R. Souza e E.F. Cypriano, Ciência e Educação 22, 65 (2016).

[3] C. Rosé e G. Siemens in: Proceedings of the EMNLP 2014 Workshop on Analysis of Large Scale Social Interaction in MOOCs (EMNLP, Doha, 2014).

[4] J.C. Almenara, M.C.L. Cejudo e A.I.V. Martínez, Revista Professorado 18, 13 (2014).

[5] G. Siemens, International Journal of Instructional Technology and Distance Learning (ITDL), disponível em https://www. semanticscholar.org/paper/Connectivism\{\%\}3AA-Learning-Theory-for-the-Digital-Age-Siemens / f87c61b964e32786e06c969fd24f5a7d9426f3b4.

[6] J. Mackness M. Waite, G. Roberts e E. Lovegrov, The international review of research in open and distance learning 14, 140 (2013).

[7] K.R. Koedinger, E.A. McLaughlin, J. Kim, J.J. Jia e N.L. Bier, Learning is Not a Spectator Sport: Doing is Better than Watching for Learning from a MOOC, disponível em https : //dl. acm.org/citation. cfm?doid=2724660. 2724681

[8] A.F. Blanco, M.L.S. Echaluce e F.G.C, Peñalvo, Universal Computer Science 21, 712 (2015).

[9] G. Christensen, A. Steinmetz, B. Alcorn, B. Bennett, D. Woods e E. Emanuel The MOOC Phenomenon: Who Takes Massive Open Online Courses and Why?, disponível em https://dx.doi.org/10.2139/ssrn.2350964.

[10] A. Damineli e D.S.C, Damineli, Estudos Avançados 21, 263 (2007).
[11] J. Mattar e S. Nesteriuk, RIED. Revista Iberoamericana de Educación a Distancia 19, 91 (2016).

[12] L. Guárdia, M. Maina e A. Sangrà, MOOC Design Principles. A Pedagogical Approach from the Learner"s Perspective, disponível em http://openaccess uoc.edu/webapps/o2/handle/10609/41681

[13] S. Kellog, Nature 499, 369 (2013).

[14] University of British Columbia, Production Guidelines at University of British Columbia (UBC, Vancouver, 2013).

[15] K.F. Colvin, J. Champaign, A. Liu, Q. Zhou, C. Fredericks e D.E. Pritchard, The international review of research in open and distance learning 15, 263 (2014).

[16] J. DeBoer in Conference: Sixth International Conference of MIT's Learning International Networks Consortium (LINC, Cambridge, 2013).

[17] A. Anderson, D. Huttenlocher, J. Kleinberg e J. Leskovec, in $W W W$ '14 Proceedings of the 23rd international conference on World wide web (ACM, New York, 2014).

[18] O. Poquet, T. Hennis e P. Vries, in Conference: EMOOCs 2015, the Third European MOOCs Stakeholders Summit, (Mons, 2015).

[19] M.M. Walldrop, Nature 495, 160 (2013).

[20] C. Impey, M. Wenger, M. Formanek e S. Buxner, Communicating Astronomy with the Public Journal 21, 20 (2016).

[21] T.J. Mahoney in Communicating Astronomy with the Public 2005: Proceedings From the ESO/ESA/IAUConference, editado por $I$.Robson e L. L. Christensen (ESA, Hubble, 2005). 